\title{
COMPUTATION OF BLAST LOADING FOR A MULTI STOREYED FRAMED BUILDING
}

\author{
Sarita Singla ${ }^{1}$, Pankaj Singla ${ }^{2}$, Anmol Singla ${ }^{3}$ \\ ${ }^{1}$ Associate Professor, Civil Engineering Department, PEC University of Technology, Chandigarh, India \\ ${ }^{2}$ Serving as Engineer in Public Works Department (Building \& Roads), Punjab, India \\ ${ }^{3}$ B.E. Student, Civil Engineering Department, PEC University of Technology, Chandigarh, India
}

\begin{abstract}
The number and intensity of domestic and international terrorist activities have heightened our concerns towards the safety of our infrastructure systems. Due to different accidental or intentional events, related to important structures all over the world, explosive loads or blast loads have received considerable attention in recent years. The development in this field is made mostly through publication of the U.S. Army Corps of Engineers, Naval Facilities Engineering Command (NAVFAC), and Air Force Civil Engineer Support Agency. In India also, the guidelines for the blast loading are published in IS 4991. In the present study, blast pressures for different weights of surface blast or TNT and varying stand-off distances are computed for a multi-storeyed framed building adopting wave scaling laws given by U.S Army technical manual (UFC3-340-02). Blast pressures for different cases are computed using correlation between blast pressure and blast scaled distance based on charts given in U.S manual. Time history loading is also obtained with parameters of reflected total over pressure and duration of positive phase of blast.
\end{abstract}

Keywords: blast loading, blast wave, scaled distance, blast pressure.

\section{INTRODUCTION}

The term blast is commonly used to describe any situation in which the rapid release of energy occurs from a chemical, mechanical or nuclear source. However, from the point of view of the effects of explosions upon structural systems, there exists a set of fundamental characteristics which must be defined and considered, irrespective of the source. Explosions occurring in urban areas or close to facilities such as buildings and protective structures may cause tremendous damage and loss of life. The immediate effects of such explosions are blast overpressures propagating through the atmosphere, fragments generated by the explosion and ground shock loads resulting from the energy imparted to the ground. Conventional buildings are constructed quite differently than hardened military structures and as such are generally quite vulnerable to blast and ballistic threats. In order to design structures which are able to withstand explosions it is necessary to first quantify the effects of such explosions. Typically, it takes a combination of specialist expertise, experimental tests, and analysis tools to properly quantify the effects. With this in mind, developers, architects and engineers increasingly are seeking solutions for potential blast situations, to protect building occupants and the structures.

Use of the TNT (Trinitrotoluene) as a reference for determining the scaled distance, $\mathrm{Z}$, is universal. The first step in quantifying the explosive wave from a source other than the TNT, is to convert the charge mass into an equivalent mass of the TNT to be considered. It is performed so that the charge mass of explosive is multiplied by the conversion factor based on the specific energy of the charge and the TNT. Specific energy of different explosive types and their conversion factors to that of the TNT are given in Table 1. [1]

Table-1: Conversion factors for various explosives

\begin{tabular}{|l|l|l|}
\hline Explosive & $\begin{array}{l}\text { Specific } \\
\text { Energy } \\
\boldsymbol{Q}_{\boldsymbol{x}} \boldsymbol{k J} / \mathbf{k g}\end{array}$ & $\begin{array}{l}\text { TNT } \\
\text { equivalent } \\
\boldsymbol{Q}_{\boldsymbol{x}} / \boldsymbol{Q}_{\boldsymbol{T N T}}\end{array}$ \\
\hline $\begin{array}{l}\text { Compound B (60\% RDX, } \\
\text { 40\% TNT) }\end{array}$ & 5190 & 1.148 \\
\hline RDX(Ciklonit) & 5360 & 1.185 \\
\hline HMX & 5680 & 1.256 \\
\hline Nitro-glycerine (liquid) & 6700 & 1.481 \\
\hline TNT & 4520 & 1.000 \\
\hline Explosive gelatine & 4520 & 1.000 \\
\hline $\begin{array}{l}\text { 60\% Nitro-glycerine } \\
\text { dynamite }\end{array}$ & 2710 & 0.600 \\
\hline Semtex & 5660 & 1.250 \\
\hline C4 & 6057 & 1.340 \\
\hline
\end{tabular}

The threat for a conventional bomb is defined by two equally important elements, the bomb size, or charge weight $W$, and the stand-off distance $R$ between the blast source and the target. The incident peak over pressures $P_{s o}$ are amplified by a reflection factor as the shock wave encounters an object or structure in its path. Except for specific focusing of high intensity shock waves at near $45^{\circ}$ incidence, these reflection factors are typically greatest for normal incidence (a surface adjacent and perpendicular to the source) and diminish with the angle of obliquity or angular position relative to the source. 
Reflection factors depend on the intensity of the shock wave, and for large explosives at normal incidence these reflection factors may enhance the incident pressures by as much as an order of magnitude.

The blast characteristics define a transient pulse of pressure which rapidly radiates out from the source of the explosion. In general terms the transient pulse will consist of a positive phase, during which the incident pressure in the medium significantly exceeds the ambient pressure, often followed by a negative phase during which the incident pressure falls below ambient. It is the interaction between this transient pulse and an affected structure which governs the dynamic response of that particular structure.

Throughout the pressure-time profile, two main phases can be observed; portion above ambient is called positive phase of duration to, while that below ambient is called negative phase of duration, to-. The negative phase is of a longer duration and a lower intensity than the positive duration. As the stand-off distance increases, the duration of the positivephase blast wave increases resulting in a lower-amplitude, longer-duration shock pulse.

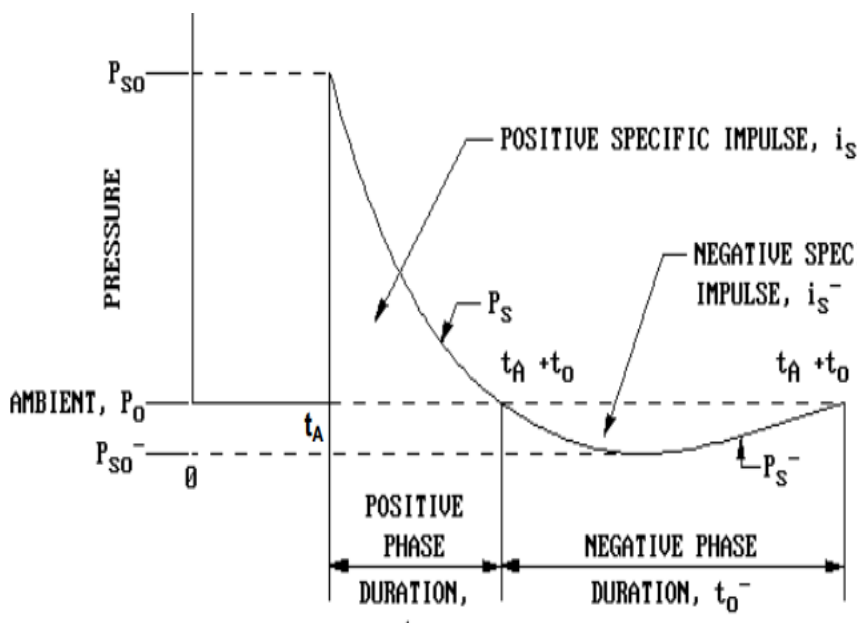

Fig-1: Typical blast pressures with time [2]

Charges situated extremely close to a target structure impose a highly impulsive, high intensity pressure load over a localized region of the structure; charges situated further away produce a lower-intensity, longer-duration uniform pressure distribution over the entire structure. Eventually, the entire structure is engulfed in the shock wave, with reflection and diffraction effects creating focusing and shadow zones in a complex pattern around the structure.

During the negative phase, the weakened structure may be subjected to impact by debris that may cause additional damage. If the exterior building walls are capable of resisting the blast load, the shock front penetrates through window and door openings, subjecting the floors, ceilings, walls, contents, and people to sudden pressures and fragments from shattered windows, doors, etc. Building components not capable of resisting the blast wave will fracture and be further fragmented and moved by the dynamic pressure that immediately follows the shock front.
Building contents and people will be displaced and tumbled in the direction of blast wave propagation. In this manner the blast will propagate through the building.

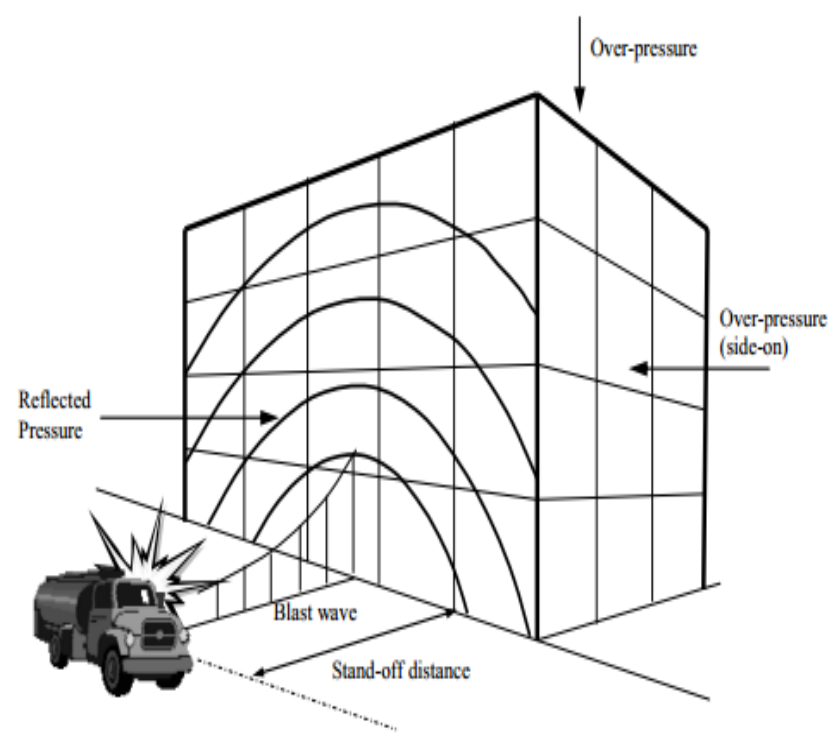

Fig-2: Blast Loads on a Building

If the exterior building walls are capable of resisting the blast load, the shock front penetrates through window and door openings, subjecting the floors, ceilings, walls, contents, and people to sudden pressures and fragments from shattered windows, doors, etc. Building components not capable of resisting the blast wave will fracture and be further fragmented and moved by the dynamic pressure that immediately follows the shock front. Building contents and people will be displaced and tumbled in the direction of blast wave propagation. In this manner the blast will propagate through the building.

\subsection{Blast Wave Scaling Laws}

All blast parameters are primarily dependent on the amount of energy released by a detonation in the form of a blast wave and the distance from the explosion. A universal normalized description of the blast effects can be given by scaling distance relative to $(E / P O)^{1 / 3}$ and scaling pressure relative to $P_{0}$, where $E$ is the energy release $(\mathrm{kJ})$ and $P_{\mathrm{o}}$ the ambient pressure (typically $100 \mathrm{kN} / \mathrm{m}^{2}$ ). For convenience, however, it is general practice to express the basic explosive input or charge weight $W$ as an equivalent mass of TNT. Results are then given as a function of the dimensional distance parameter. Scaling laws provide parametric correlations between a particular explosion and a standard charge of the same substance.

$$
\text { Scaled distance }(\mathrm{Z})=\frac{\mathrm{R}}{\mathrm{W}^{1 / 3}}
$$

Where, $R$ is the actual effective distance from the explosion $W$ is generally expressed in pounds or kilograms. 


\subsection{Methods for Determination of Blast Pressure}

The estimations of peak overpressure due to spherical blast based on scaled distance $\mathrm{Z}=\mathrm{R} / \mathrm{W}^{1 / 3}$ was introduced by Brode [3] as:

$$
\begin{gathered}
\mathrm{P}_{\mathrm{so}}=\frac{6.7}{Z^{3}}+1 \operatorname{bar}\left(\mathrm{P}_{\mathrm{so}}>10 b a r\right) \\
\mathrm{P}_{\mathrm{so}}=\frac{0.975}{Z}+\frac{1.455}{Z^{2}}+\frac{5.85}{Z^{3}}-0.019 \operatorname{bar}(0.1<\mathrm{Pso}<10 \mathrm{bar})
\end{gathered}
$$

In 1961, Newmark [4] introduced a relationship to calculate the maximum blast pressure $\left(\mathrm{P}_{\mathrm{so}}\right)$, in bars, for a high explosive charge detonates at the ground surface as:

$$
\mathrm{P}_{\mathrm{so}}=6784 \frac{W}{R^{3}}+93\left(\frac{W}{R^{3}}\right)^{1 / 2}
$$

In 1987, Mills [5] introduces another expression of the peak overpressure in $\mathrm{kPa}$, in which $\mathrm{W}$ is the equivalent charge weight in kilograms of TNT and Z is the scaled distance.

$$
\mathrm{P}_{\mathrm{so}}=\frac{1772}{Z^{3}}+\frac{114}{Z^{2}}+\frac{108}{Z}
$$

If the blast wave encounters an obstacle perpendicular to the direction of propagation, reflection increases the overpressure to a maximum reflected pressure $\mathrm{P}_{\mathrm{r}}$ as:

$$
\mathrm{P}_{\mathrm{r}}=2 \mathrm{P}_{\mathrm{so}}\left(\frac{7 P_{0}+4 P_{S o}}{7 P_{0}+P_{s o}}\right)
$$

A full discussion and extensive charts for predicting blast pressures and blast durations are given by Mays and Smith [6] and UFC 3-340-02 (2008).

$P_{r}=$ Peak Reflected Overpressure

$P_{s o}=$ Peak Static Pressure

$i_{r}=$ Impact due to reflected overpressure

$i_{s}=$ Impact due to static pressure

$t_{A}=$ Arrival time

$t_{O}=$ Positive phase duration

$U=$ Blast wave velocity

$L_{w}=$ Length of Blast wave

For design purposes, reflected overpressure can be idealized by an equivalent triangular pulse of maximum peak pressure $P_{r}$ and time duration $t_{d}$, which yields the reflected impulse $\left(i_{r}\right)$.

$$
\text { Reflected Impulse }\left(i_{r}\right)=\frac{1}{2} P_{r} t_{d}
$$

Duration $t_{d}$ is related directly to the time taken for the overpressure to be dissipated. Overpressure arising from wave reflection dissipates as the perturbation propagates to the edges of the obstacle at a velocity related to the speed of sound $\left(U_{s}\right)$ in the compressed and heated air behind the wave front. Denoting the maximum distance from an edge as $\mathrm{S}$ (for example, the lesser of the height or half the width of a conventional building), the additional pressure due to reflection is considered to reduce from $P_{r}-P_{s o}$ to zero in time $3 S / U_{s}$. Conservatively, $U_{s}$ can be taken as the normal speed of sound, which is about $340 \mathrm{~m} / \mathrm{s}$, and the additional impulse to the structure evaluated on the assumption of a linear decay. After the blast wave has passed the rear corner of a prismatic obstacle, the pressure similarly propagates on to the rear face; linear build-up over duration $5 S / U_{s}$ has been suggested. For skeletal structures the effective duration of the net overpressure load is thus small, and the drag loading based on the dynamic pressure is then likely to be dominant. Conventional wind loading pressure coefficients may be used, with the conservative assumption of instantaneous build-up when the wave passes the plane of the relevant face of the building, the loads on the front and rear faces being numerically cumulative for the overall load effect on the structure. Various formulations have been put forward for the rate of decay of the dynamic pressure loading; a parabolic decay (i.e. corresponding to a linear decay of equivalent wind velocity) over a time equal to the total duration of positive overpressure is a practical approximation. 


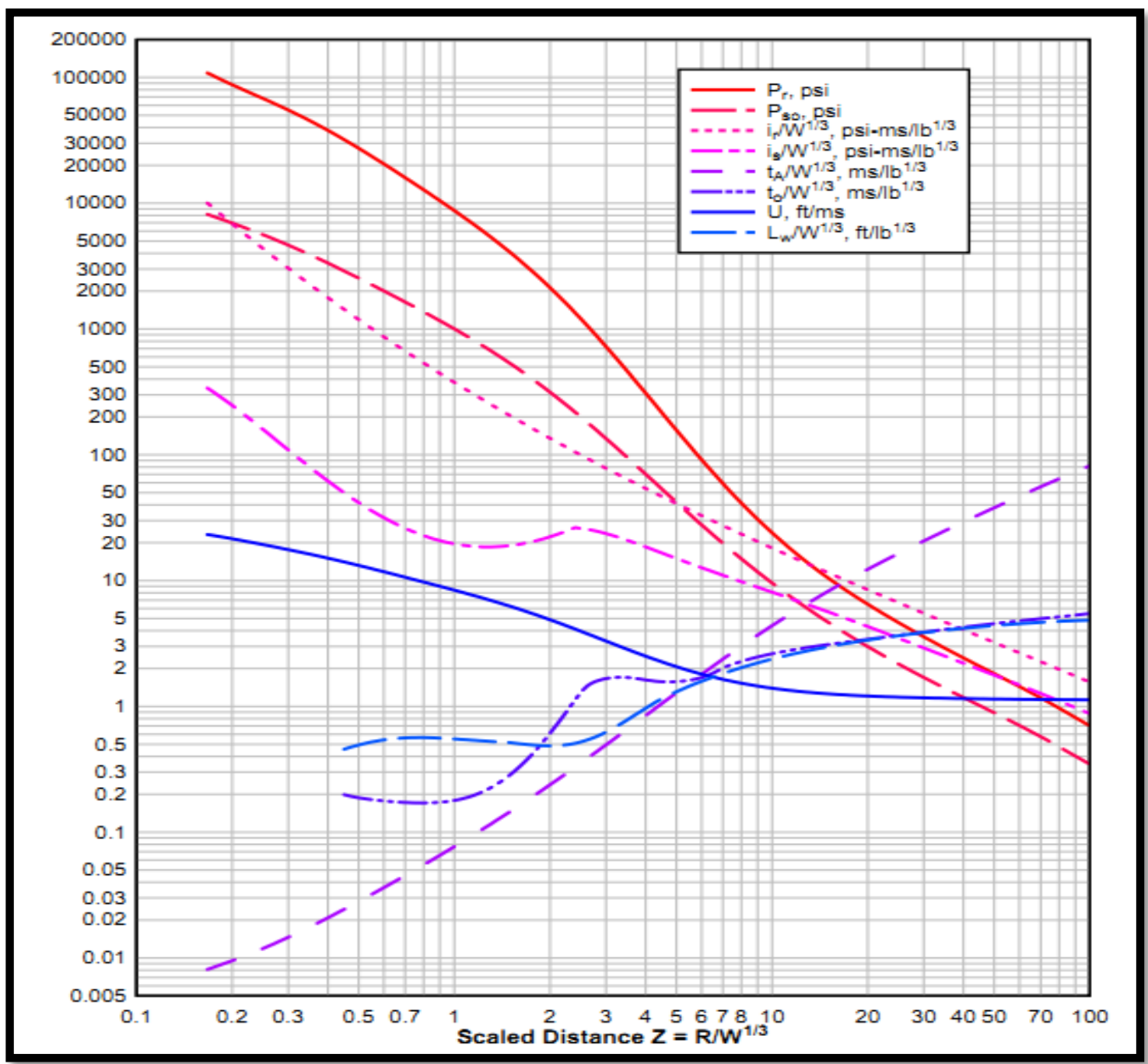

Fig-3: Positive phase shock wave parameters for a hemispherical TNT explosion on the surface at sea level [2]

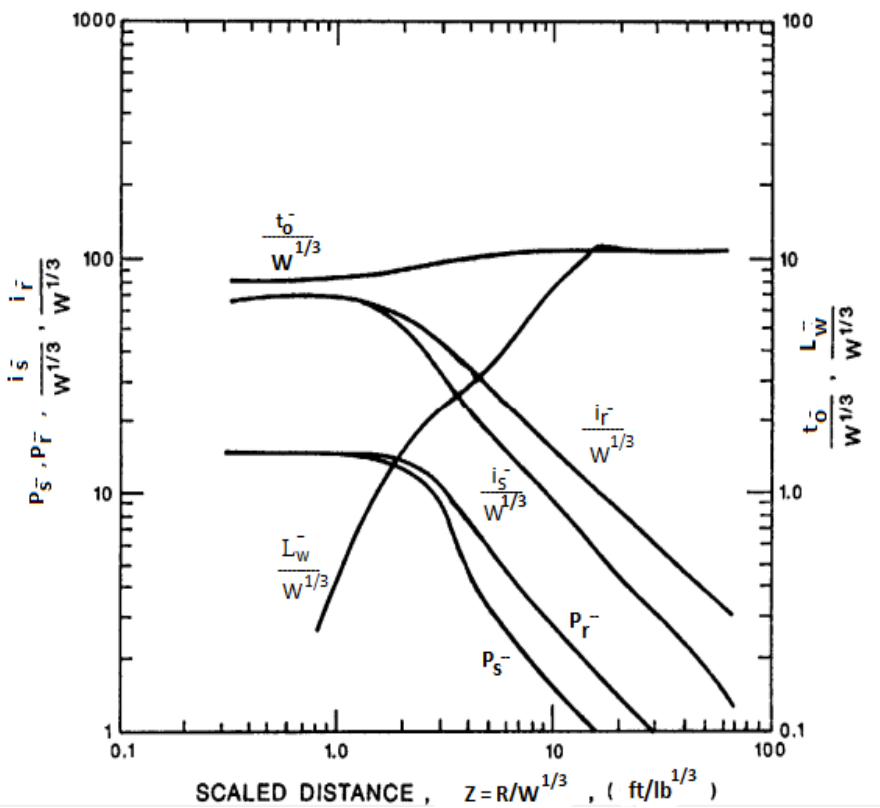

2. COMPUTATION OF BLAST LOADING FOR

\section{A THREE STOREYED FRAMED BUILDING}

Computation of blast loading for a three storeyed framed building has been carried out for the three cases of blast loading. Three categories of buildings are considered as per IS code 4991:1968 for blast resistant designing purposes. In the first case the equivalent TNT charge weight W has been taken as $100 \mathrm{Kg}$ and the actual effective distance from explosion i.e. $\mathrm{R}$ is taken as $20 \mathrm{~m}, 30 \mathrm{~m}$, and $40 \mathrm{~m}$. In the second case $\mathrm{W}$ has been taken as $200 \mathrm{Kg}$ and $\mathrm{R}$ as $20 \mathrm{~m}, 30$ $\mathrm{m}, 40 \mathrm{~m}$ and in the third case charge weight $\mathrm{W}$ has been taken as $300 \mathrm{Kg} \& \mathrm{R}$ is again varied as $20 \mathrm{~m}, 30 \mathrm{~m}, 40 \mathrm{~m}$. Height of building is $9 \mathrm{~m}$. The plan and elevation of the building is shown below:

Fig-4: Negative phase shock wave parameters for hemi spherical TNT explosion on the surface at sea level [2] 


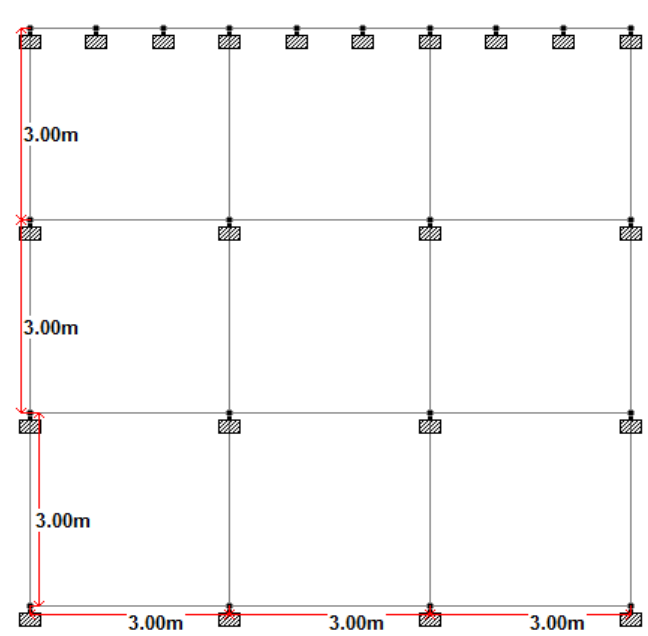

Fig-5: Plan of the building

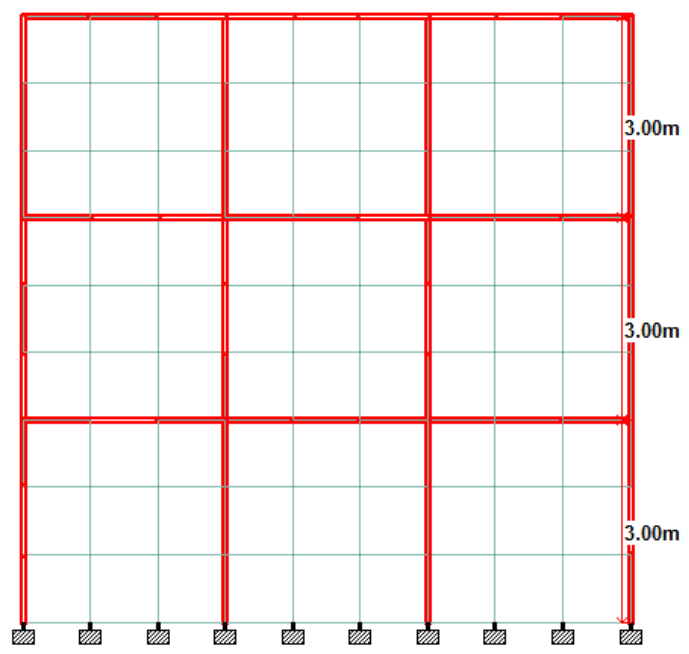

Fig-6: Elevation of the building



Fig-7: Isometric view of the building

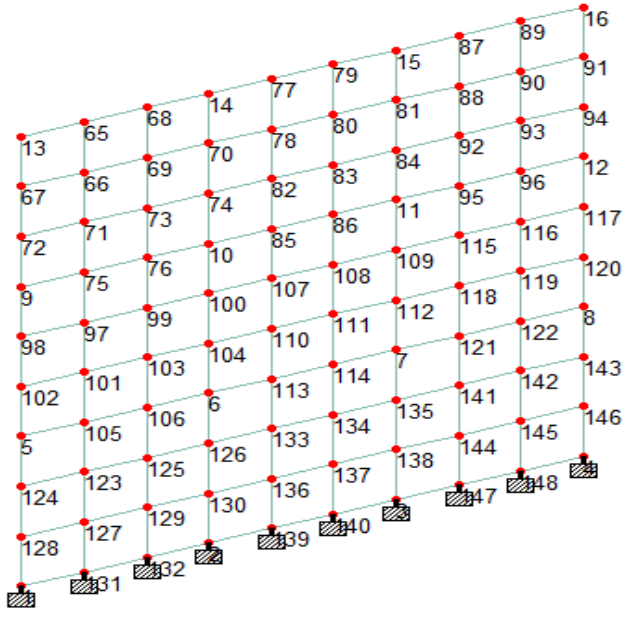

Fig-8: Nodes which are subjected to blast forces

\subsection{Blast Pressure Parameters as per UFC 3-340-02}

Case 1(a)

$\mathrm{W}=100 \mathrm{~kg}$ or $220.46 \mathrm{lbs}$

Stand-off distance at ground level, $\mathrm{R}=20 \mathrm{~m}$ or $65.61 \mathrm{ft}$

Factor of safety $=1.2$

$\mathrm{W}^{\prime}=1.2 \times 220.46=264.55 \mathrm{lbs}$

Scaled Distance $Z=R / \mathrm{W}^{1 / 3}=10.22 \mathrm{ft} / \mathrm{lb}^{1 / 3}$

For $Z=10.22 \mathrm{ft} / \mathrm{lb}^{1 / 3}$, (Refer Fig.3)

Peak Reflected Overpressure $\mathrm{P}_{\mathrm{r}}=22 \mathrm{psi}$

Peak static pressure $\mathrm{P}_{\mathrm{so}}=9 \mathrm{psi}$

$\mathrm{t}_{\mathrm{A}} / \mathrm{W}^{1 / 3}=4.5$

Arrival Time $\mathrm{t}_{\mathrm{A}}=28.88 \mathrm{~ms}$

$\mathrm{t}_{\mathrm{o}} / \mathrm{W}^{1 / 3}=2.5$

Duration of positive blast wave $t_{\mathrm{o}}=16.04 \mathrm{~ms}$

$\mathrm{Z}$ At $1 \mathrm{~m}$ Height $=10.23 \mathrm{ft} / \mathrm{lb}^{1 / 3}$,

Peak Reflected Overpressure $\mathrm{P}_{\mathrm{r}}=21.99$ psi

Peak static pressure $\mathrm{P}_{\mathrm{so}}=8.99 \mathrm{psi}$

$\mathrm{t}_{\mathrm{A}} / \mathrm{W}^{1 / 3}=4.5$

Arrival Time $t_{\mathrm{A}}=28.88 \mathrm{~ms}$

$\mathrm{t}_{\mathrm{o}} / \mathrm{W}^{1 / 3}=2.5$

Duration of positive blast wave $t_{0}=16.04 \mathrm{~ms}$

As the height of building increases, Scaled distance increases correspondingly and the value of blast pressure reduces by some amount. The blast parameters along the height of the building are shown in Table 2 to Table 8 for all the three categories of buildings.

Table-2: Blast parameters for $\mathrm{W}=100 \mathrm{~kg}$ and $\mathrm{R}=20 \mathrm{~m}$

\begin{tabular}{|l|l|l|l|l|l|}
\hline Ht. $(\mathrm{m})$ & $\mathrm{Z}$ & $\mathrm{P}_{\mathrm{r}}(\mathrm{psi})$ & $\mathrm{P}_{\mathrm{so}}(\mathrm{psi})$ & $\mathrm{t}_{\mathrm{A}}(\mathrm{ms})$ & $\mathrm{t}_{\mathrm{o}}(\mathrm{ms})$ \\
\hline 0 & 10.22 & 22 & 9 & 28.88 & 16.04 \\
\hline 1 & 10.23 & 21.99 & 8.99 & 28.88 & 16.04 \\
\hline 2 & 10.27 & 21.95 & 8.96 & 29.08 & 16.24 \\
\hline 3 & 10.33 & 21.91 & 8.90 & 29.27 & 16.49 \\
\hline 4 & 10.42 & 21.87 & 8.86 & 29.40 & 16.62 \\
\hline 5 & 10.53 & 21.84 & 8.83 & 29.52 & 16.69 \\
\hline 6 & 10.66 & 21.80 & 8.79 & 29.59 & 16.75 \\
\hline 7 & 10.82 & 21.77 & 8.76 & 29.65 & 16.81 \\
\hline 8 & 11.00 & 21.74 & 8.71 & 29.72 & 16.88 \\
\hline 9 & 11.20 & 21.70 & 8.68 & 29.78 & 16.88 \\
\hline
\end{tabular}


Table-3: Blast parameters for $\mathrm{W}=200 \mathrm{~kg}$ and $\mathrm{R}=20 \mathrm{~m}$

\begin{tabular}{|l|l|l|l|l|l|}
\hline $\begin{array}{l}\text { Ht. } \\
(\mathrm{m})\end{array}$ & $\mathrm{Z}$ & $\mathrm{P}_{\mathrm{r}}(\mathrm{psi})$ & $\begin{array}{l}\mathrm{P}_{\mathrm{so}} \\
(\mathrm{psi})\end{array}$ & $\mathrm{t}_{\mathrm{A}}(\mathrm{ms})$ & $\mathrm{t}_{\mathrm{o}}(\mathrm{ms})$ \\
\hline 0 & 8.11 & 39 & 15 & 25.07 & 18.76 \\
\hline 1 & 8.12 & 38.99 & 14.99 & 25.15 & 18.76 \\
\hline 2 & 8.15 & 38.95 & 14.96 & 25.39 & 19 \\
\hline 3 & 8.20 & 38.92 & 14.91 & 25.55 & 19.16 \\
\hline 4 & 8.27 & 38.86 & 14.88 & 25.72 & 19.33 \\
\hline 5 & 8.36 & 38.70 & 14.72 & 25.88 & 19.49 \\
\hline 6 & 8.46 & 38 & 14.50 & 25.96 & 19.65 \\
\hline 7 & 8.59 & 37.92 & 14.35 & 26.04 & 19.735 \\
\hline 8 & 8.73 & 37.80 & 14.29 & 26.12 & 19.816 \\
\hline 9 & 8.89 & 37.70 & 14.24 & 26.20 & 19.89 \\
\hline
\end{tabular}

Table-4: Blast parameters for $\mathrm{W}=200 \mathrm{~kg}$ and $\mathrm{R}=30 \mathrm{~m}$

\begin{tabular}{|l|l|l|l|l|l|}
\hline $\begin{array}{l}\text { Ht. } \\
\mathrm{m})\end{array}$ & $\mathrm{Z}$ & $\mathrm{P}_{\mathrm{r}}(\mathrm{psi})$ & $\begin{array}{l}\mathrm{P}_{\mathrm{so}} \\
(\mathrm{psi})\end{array}$ & $\mathrm{t}_{\mathrm{A}}(\mathrm{ms})$ & $\mathrm{t}_{\mathrm{o}}(\mathrm{ms})$ \\
\hline 0 & 12.16 & 18.5 & 8 & 41.24 & 22.64 \\
\hline 1 & 12.16 & 18.5 & 8 & 41.24 & 22.64 \\
\hline 2 & 12.19 & 18.47 & 7.98 & 41.41 & 22.88 \\
\hline 3 & 12.22 & 18.40 & 7.5 & 41.65 & 23.05 \\
\hline 4 & 12.27 & 18.2 & 7.3 & 41.89 & 23.45 \\
\hline 5 & 12.33 & 18.1 & 7.1 & 41.97 & 23.53 \\
\hline 6 & 12.40 & 18.0 & 7 & 42.05 & 23.69 \\
\hline 7 & 12.49 & 17.98 & 6.99 & 42.13 & 23.77 \\
\hline 8 & 12.59 & 17.95 & 6.95 & 42.21 & 23.79 \\
\hline 9 & 12.70 & 17.90 & 6.90 & 42.30 & 23.82 \\
\hline
\end{tabular}

Table-5: Blast parameters for $\mathrm{W}=200 \mathrm{~kg}$ and $\mathrm{R}=40 \mathrm{~m}$

\begin{tabular}{|l|l|l|l|l|l|}
\hline $\begin{array}{l}\text { Ht. } \\
(\mathrm{m})\end{array}$ & $\mathrm{Z}$ & $\mathrm{P}_{\mathrm{r}}(\mathrm{psi})$ & $\begin{array}{l}\mathrm{P}_{\mathrm{so}} \\
(\mathrm{psi})\end{array}$ & $\mathrm{t}_{\mathrm{A}}(\mathrm{ms})$ & $\mathrm{t}_{\mathrm{o}}(\mathrm{ms})$ \\
\hline 0 & 16.28 & 10 & 4.5 & 66.87 & 24.97 \\
\hline 1 & 16.28 & 10 & 4.5 & 66.87 & 24.97 \\
\hline 2 & 16.30 & 9.99 & 4.49 & 67.03 & 25.21 \\
\hline 3 & 16.33 & 9.97 & 4.46 & 67.11 & 25.21 \\
\hline 4 & 16.36 & 9.95 & 4.45 & 67.19 & 25.30 \\
\hline 5 & 16.41 & 9.92 & 4.43 & 67.20 & 25.30 \\
\hline 6 & 16.46 & 9.91 & 4.42 & 67.22 & 25.33 \\
\hline 7 & 16.53 & 9.90 & 4.41 & 67.23 & 25.34 \\
\hline 8 & 16.60 & 9.89 & 4.40 & 67.24 & 25.35 \\
\hline 9 & 16.69 & 9.87 & 4.39 & 67.25 & 25.36 \\
\hline
\end{tabular}

Table-6: Blast parameters for $\mathrm{W}=300 \mathrm{~kg}$ and $\mathrm{R}=20 \mathrm{~m}$

\begin{tabular}{|l|l|l|l|l|l|}
\hline $\begin{array}{l}\text { Ht. } \\
(\mathrm{m})\end{array}$ & $\mathrm{Z}$ & $\mathrm{P}_{\mathrm{r}}(\mathrm{psi})$ & $\begin{array}{l}\mathrm{P}_{\mathrm{so}} \\
(\mathrm{psi})\end{array}$ & $\mathrm{t}_{\mathrm{A}}(\mathrm{ms})$ & $\mathrm{t}_{\mathrm{o}}(\mathrm{ms})$ \\
\hline 0 & 7.08 & 55 & 20 & 22.22 & 18.51 \\
\hline 1 & 7.09 & 54.9 & 19.9 & 22.22 & 18.51 \\
\hline 2 & 7.12 & 54.00 & 19.00 & 22.31 & 19.44 \\
\hline 3 & 7.16 & 53.5 & 18.5 & 22.49 & 19.72 \\
\hline 4 & 7.22 & 53.0 & 18.0 & 22.68 & 19.99 \\
\hline 5 & 7.30 & 51.0 & 17.9 & 22.86 & 20.09 \\
\hline 6 & 7.39 & 50 & 17.5 & 22.96 & 20.18 \\
\hline 7 & 7.50 & 49.5 & 17.1 & 23.14 & 20.27 \\
\hline 8 & 7.63 & 49 & 16.9 & 23.33 & 20.36 \\
\hline 9 & 7.76 & 48.5 & 16.7 & 23.42 & 20.46 \\
\hline
\end{tabular}

Table-7: Blast parameters for $\mathrm{W}=300 \mathrm{~kg}$ and $\mathrm{R}=30 \mathrm{~m}$

\begin{tabular}{|l|l|l|l|l|l|}
\hline $\begin{array}{l}\text { Ht. } \\
(\mathrm{m})\end{array}$ & $\mathrm{Z}$ & $\mathrm{P}_{\mathrm{r}}(\mathrm{psi})$ & $\begin{array}{l}\mathrm{P}_{\mathrm{so}} \\
(\mathrm{psi})\end{array}$ & $\mathrm{t}_{\mathrm{A}}(\mathrm{ms})$ & $\mathrm{t}_{\mathrm{o}}(\mathrm{ms})$ \\
\hline 0 & 10.63 & 21.80 & 8.80 & 42.58 & 24.07 \\
\hline 1 & 10.63 & 21.80 & 8.80 & 42.58 & 24.07 \\
\hline 2 & 10.65 & 21.78 & 8.79 & 42.58 & 24.25 \\
\hline 3 & 10.68 & 21.77 & 8.78 & 42.77 & 24.25 \\
\hline 4 & 10.72 & 21.75 & 8.75 & 42.86 & 24.25 \\
\hline 5 & 10.77 & 21.70 & 8.71 & 42.95 & 24.35 \\
\hline 6 & 10.83 & 21.6 & 8.67 & 43.05 & 24.44 \\
\hline 7 & 10.90 & 21.55 & 8.65 & 43.19 & 24.48 \\
\hline 8 & 10.98 & 21.51 & 8.61 & 43.29 & 24.51 \\
\hline 9 & 11.08 & 21.48 & 8.57 & 43.33 & 24.55 \\
\hline
\end{tabular}

Table-8: Blast parameters for $\mathrm{W}=300 \mathrm{~kg}$ and $\mathrm{R}=40 \mathrm{~m}$

\begin{tabular}{|l|l|l|l|l|l|}
\hline $\begin{array}{l}\text { Ht. } \\
(\mathrm{m})\end{array}$ & $\mathrm{Z}$ & $\mathrm{P}_{\mathrm{r}}(\mathrm{psi})$ & $\begin{array}{l}\mathrm{P}_{\mathrm{so}} \\
(\mathrm{psi})\end{array}$ & $\mathrm{t}_{\mathrm{A}}(\mathrm{ms})$ & $\mathrm{t}_{\mathrm{o}}(\mathrm{ms})$ \\
\hline 0 & 14.17 & 12 & 5.1 & 64.80 & 26.84 \\
\hline 1 & 14.17 & 12 & 5.1 & 64.80 & 26.84 \\
\hline 2 & 14.19 & 11.98 & 5.0 & 64.90 & 26.94 \\
\hline 3 & 14.21 & 11.96 & 4.99 & 65.27 & 26.94 \\
\hline 4 & 14.24 & 11.93 & 4.97 & 65.55 & 27.03 \\
\hline 5 & 14.28 & 11.91 & 4.96 & 65.73 & 27.12 \\
\hline 6 & 14.33 & 11.90 & 4.95 & 65.82 & 27.12 \\
\hline 7 & 14.38 & 11.89 & 4.94 & 65.92 & 27.22 \\
\hline 8 & 14.45 & 11.88 & 4.93 & 66.01 & 27.31 \\
\hline 9 & 14.52 & 11.87 & 4.92 & 66.10 & 27.40 \\
\hline
\end{tabular}

These blasts reflected overpressures are applied to the front side of building in form of blast force. To obtain blast forces these pressures are multiplied with the contributing area of each node. Sample calculations for forces acting on the nodes due to blast weight of $100 \mathrm{~kg}$ at standoff distance of $20 \mathrm{~m}$ are shown below:

\section{At Ground Floor}

For outer nodes (Node no 1, Node no. 4)

$\mathrm{P}_{\mathrm{r}}=22 \mathrm{psi}=0.022 \mathrm{ksi}=.022 \times 6.895=0.15169 \mathrm{MPa}$

Blast Force $\mathrm{P}_{1}=0.15169 \times 0.25 \times 1000=37.92 \mathrm{kN}$

For inner nodes $\mathrm{P}_{\mathrm{ro}}=0.15169 \mathrm{MPa}$

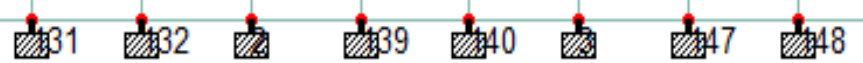

Blast Force $\mathrm{P}_{2}=0.1516 \times 0.5 \times 1000=75.84 \mathrm{kN}$

\section{At $1 \mathrm{~m}$ Height of Building}

For outer nodes, (Node no 128, Node no. 146) $\mathrm{P}_{\mathrm{r}}=21.99 \mathrm{psi}=0.15162 \mathrm{MPa}$

Blast Force $\mathrm{P}_{3}=0.15162 \times 0.5 \times 1000=75.81 \mathrm{kN}$ For inner nodes,

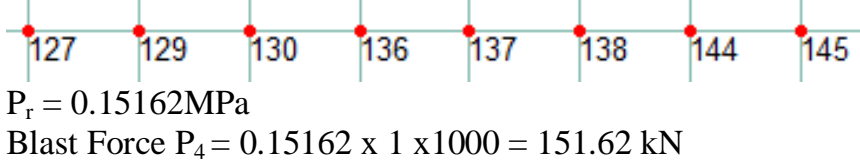




\section{At $2 \mathrm{~m}$ Height of Building}

For outer nodes, (Node no 124, Node no. 143)

$\mathrm{P}_{\mathrm{r}}=21.95 \mathrm{psi}=0.15134 \mathrm{MPa}$

Blast Force $\mathrm{P}_{5}=0.15134 \times 0.5 \times 1000=75.67 \mathrm{kN}$

For inner nodes,

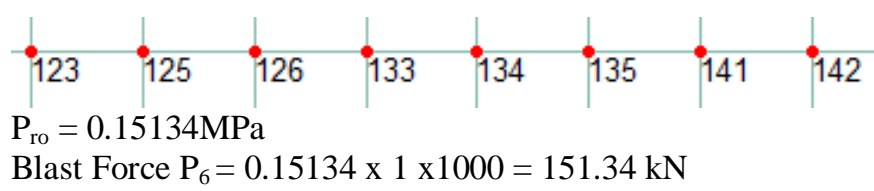

\section{At 3 m Height of Building}

For outer nodes,(Node no 5, Node no. 8)

Blast Force $\mathrm{P}_{7}=75.53 \mathrm{kN}$

For inner nodes,

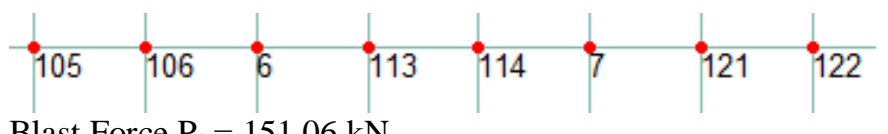

Blast Force $\mathrm{P}_{8}=151.06 \mathrm{kN}$

\section{At 4 m Height of Building}

For outer nodes,(Node no 102, Node no. 120)

Blast Force $\mathrm{P}_{9}=75.39 \mathrm{kN}$

For inner nodes,

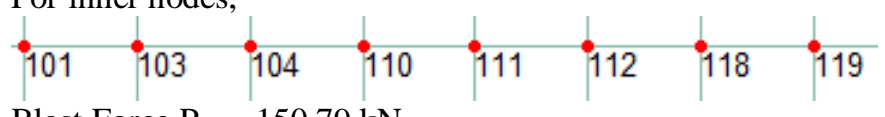

Blast Force $\mathrm{P}_{10}=150.79 \mathrm{kN}$

\section{At 5 m Height of Building}

For outer nodes, (Node no 98, Node no. 117)

Blast Force $\mathrm{P}_{11}=75.29 \mathrm{kN}$

For inner nodes,

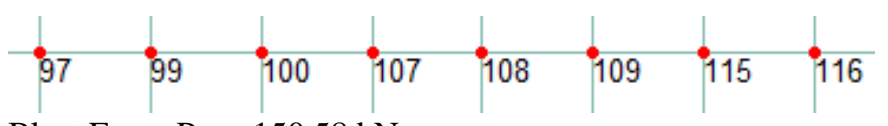

Blast Force $\mathrm{P}_{12}=150.58 \mathrm{kN}$

\section{At 6 m Height of Building}

For outer nodes,(Node no 9, Node no. 12)

Blast Force $\mathrm{P}_{13}=75.15 \mathrm{kN}$

For inner nodes,

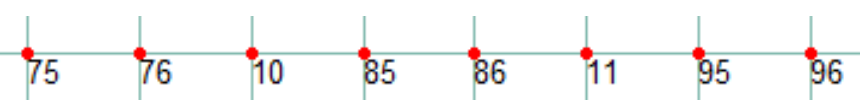

Blast Force $\mathrm{P}_{14}=150.311 \mathrm{kN}$

\section{At 7 m Height of Building}

For outer nodes, (Node no 72, Node no. 94)

Blast Force $\mathrm{P}_{15}=75.05 \mathrm{kN}$

For inner nodes,

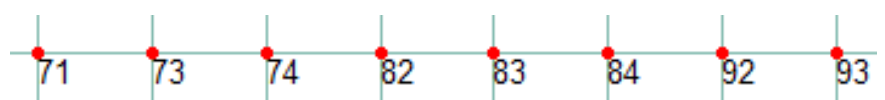

Blast Force $\mathrm{P}_{16}=150.10 \mathrm{kN}$

\section{At 8 m Height of Building}

For outer nodes,(Node no 67, Node no. 91)

Blast Force $\mathrm{P}_{17}=74.94 \mathrm{kN}$

For inner nodes,

\begin{tabular}{ll|llllll}
66 & 69 & 70 & 78 & 80 & 81 & 88 & 90 \\
Blast Force $\mathrm{P}_{18}=$ & $149.89 \mathrm{kN}$ & & & &
\end{tabular}

\section{At $9 \mathrm{~m}$ Height of Building}

For outer nodes,(Node no 13, Node no. 16)

Blast Force $\mathrm{P}_{19}=37.50 \mathrm{kN}$

For inner nodes,

$\begin{array}{lllllll}65 & 68 & 14 & 79 & 15 & 87 & 89\end{array}$

\section{VARIATION OF BLAST PRESSURES}

Table-9: Blast parameters for $\mathrm{W}=100 \mathrm{~kg}$ with different values of stand-off distance ' $R$ '

\begin{tabular}{|l|l|l|l|}
\hline $\mathbf{R}(\mathbf{m})$ & $\mathbf{Z}\left(\mathbf{f t} / \mathbf{l b}^{\mathbf{1} / \mathbf{3}}\right)$ & $\mathbf{P}_{\mathbf{r}}(\mathbf{p s i})$ & $\mathbf{P}_{\text {so }}(\mathbf{p s i})$ \\
\hline 20 & 10.22 & 22 & 9 \\
\hline 30 & 15.33 & 11 & 4.9 \\
\hline 40 & 20.44 & 6.1 & 2.9 \\
\hline
\end{tabular}

Table-10: Blast parameters for $\mathrm{W}=200 \mathrm{~kg}$ with different values of stand-off distance ' $R$ '

\begin{tabular}{|l|l|l|l|}
\hline $\mathbf{R}(\mathbf{m})$ & $\mathbf{Z}\left(\mathbf{f t} / \mathbf{l b}^{\mathbf{1 / 3}}\right)$ & $\mathbf{P}_{\mathbf{r}}(\mathbf{p s i})$ & $\mathbf{P}_{\text {so }}(\mathbf{p s i})$ \\
\hline 20 & 8.11 & 39 & 15 \\
\hline 30 & 12.16 & 18.5 & 8 \\
\hline 40 & 16.28 & 10 & 4.5 \\
\hline
\end{tabular}

Table-11: Blast parameters for $\mathrm{W}=300 \mathrm{~kg}$ with different values of stand-off distance ' $R$ '

\begin{tabular}{|l|l|l|l|}
\hline $\mathbf{R}(\mathbf{m})$ & $\begin{array}{l}\mathbf{Z} \\
\left(\mathbf{f t} / \mathbf{l} \mathbf{b}^{\mathbf{1 / 3}}\right)\end{array}$ & $\mathbf{P}_{\mathbf{r}}(\mathbf{p s i})$ & $\mathbf{P}_{\text {so }}(\mathbf{p s i})$ \\
\hline 20 & 7.08 & 55 & 20 \\
\hline 30 & 10.63 & 21.80 & 8.80 \\
\hline 40 & 14.17 & 12 & 5.1 \\
\hline
\end{tabular}




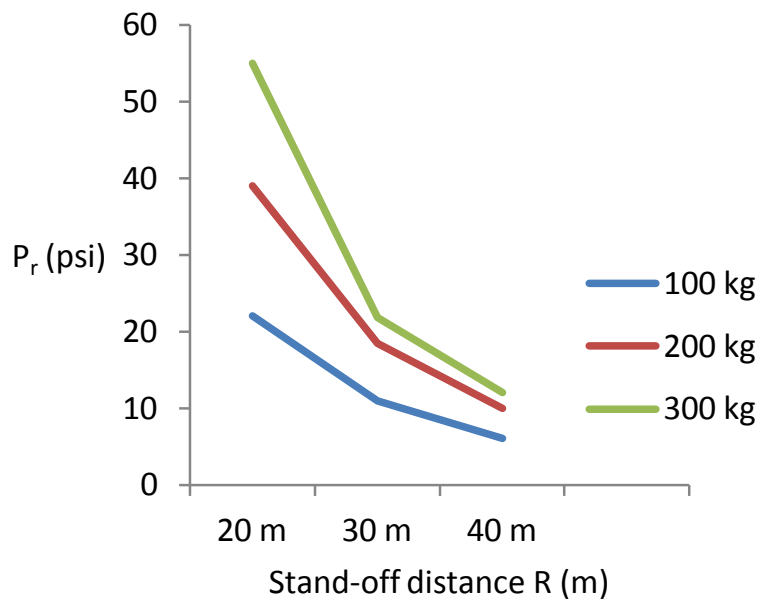

Fig-9: Peak reflected overpressure v/s Stand-off distance R for different blast weights.

From above results it is clear that as the stand-off distance increases from the building, the magnitude of blast pressure reduces significantly. Fig 9 shows that blast parameters are greatly dependent on weight of blast and stand-off distance. As the weight of blast increases i.e. from $100 \mathrm{~kg}$ to $200 \mathrm{~kg}$ at stand-off distance of $20 \mathrm{~m}$, the pressure increases by $77.27 \%$ and when the blast weight increases from $100 \mathrm{~kg}$ to $300 \mathrm{~kg}$ at same distance then the pressure increases by $150 \%$. For all the three cases which are discussed above, blast pressure increases as weight of blast increases and blast pressure decreases when stand-off distance increases. If the stand-off distance increases from 20 to $30 \mathrm{~m}$ for $100 \mathrm{~kg}$ blast weight then the blast pressure reduces by $50 \%$ and if distance changes from 20 to $40 \mathrm{~m}$ for $100 \mathrm{~kg}$ blast, then the pressure reduces by $72.27 \%$. It was also observed that if the distance of blast changes from 20 to $30 \mathrm{~m}$ for $200 \mathrm{~kg}$ of blast then the blast pressure reduces by $52 \%$ and if distance of blast changes from 20 to $40 \mathrm{~m}$ for $200 \mathrm{~kg}$ blast, then the pressure reduces by $74.35 \%$. For $300 \mathrm{~kg}$ blast weight, the pressure reduces by $60.36 \%$ and $78.18 \%$ if the stand-off distance changes from 20 to $30 \mathrm{~m}$ and 20 to $30 \mathrm{~m}$ respectively. It clearly depicts the dependency of blast parameters on R/W ratio.

\section{CONCLUSION}

The following observations and conclusions are drawn from this study:

1. Peak static pressure $P_{\text {so }}$ is found to be increasing as the weight of blast increases. Peak static pressure increases by $66.6 \%$ if the blast weight increases from $100 \mathrm{~kg}$ to $200 \mathrm{~kg}$. If the value of blast weight increases from $100 \mathrm{~kg}$ to $300 \mathrm{~kg}$ then the value of peak static pressure increases by $122 \%$ at a stand-off distance of $20 \mathrm{~m}$.It shows the dependency of blast pressures on weight of TNT or blast.

2. Peak static pressure $P_{\text {so }}$ is decreasing as the stand-off distance increases. Peak static pressure decreases by $45 \%$ to $50 \%$ if the stand-off distance changes from 20 to $30 \mathrm{~m}$. On further increasing the stand-off distance i.e. from 20 to $40 \mathrm{~m}$, the value of pressure decreases by approximately $65 \%$ to $70 \%$.It shows the dependency of blast pressures on stand-off distance of explosion from the building.

3. Peak reflected overpressure $P_{r}$ is increasing as the weight of blast increases. Peak reflected overpressure increases by $77.27 \%$ if the blast weight increases from $100 \mathrm{~kg}$ to $200 \mathrm{~kg}$. If the value of blast weight increases from $100 \mathrm{~kg}$ to $300 \mathrm{~kg}$ then the value of peak reflected pressure increases by $150 \%$ at a stand-off distance of $20 \mathrm{~m}$. It shows the dependency of blast pressures on weight of TNT or blast.

4. Peak reflected overpressure $P_{r}$ was decreasing as the stand-off distance increases. Peak reflected overpressure decreases by $50 \%$, if standoff distance changes from 20 to $30 \mathrm{~m}$. On further increasing the stand-off distance i.e. from 20 to $40 \mathrm{~m}$, the value of pressure decreases by approximately $75 \%$. It shows the dependency of blast pressures on stand-off distance of explosion from the building.

5. Effect of peak static pressure and peak reflected overpressure was more at ground storey than upper storeys and their effect decreases almost linearly by $3.5 \%$ to $10 \%$ approximately at a height of $9 \mathrm{~m}$.

6. Blast waves take milliseconds to reach the building from site of explosion and affect the building.

7. From above computations of blast pressures, it was observed that blast pressure was inversely proportional to blast scaled distance $(Z)$.

\section{REFERENCES}

[1] Draganic, H. \& Sigmund, V., "Blast Loading On Structures." J.J Strossmayer University of Osijek.

[2] UFC 3-340-02, 5 December 2008. United Facilities Criteria, "Structures to resist the effects of accidental explosions."

[3] Brode, H.L., 1995, "Numerical solution of spherical blast waves", Journal of Applied Physics, June, No.6.

[4] Newmark, N. M., and Hansen R.J. 1961, "Design of blast resistant structures." Shock and vibration Handbook, Vol. 3, Eds. Harris and Crede, McGrawHill, New York, USA.

[5] Mills C.A., "The design of concrete structure to resist explosion and weapon effects," Proceedings of the first International conference on concrete for hazard protections, Edinburgh, UK, pp 61-73, 1987.

[6] Mays, G.C., and P.D. Smith., 1995, Blast effects on Buildings. London: Thomas Telford Publications. 